\title{
Editorial
}

Journal of Innate

Immunity

\section{Innate Immunity in Cystic Fibrosis: Novel Pieces of the Puzzle}

\author{
Hasan-Halit Öz $z^{a}$ Dominik Hart| $\left.\right|^{a, b}$ \\ ${ }^{a}$ Children's Hospital and Interdisciplinary Center for Infectious Diseases, University of Tübingen, Tübingen, \\ Germany; ${ }^{b}$ Immunology, Inflammation and Infectious Diseases (I3) Discovery and Translational Area, \\ Roche Pharma Research \& Early Development (pRED), Roche Innovation Center Basel, Basel, Switzerland
}

Cystic fibrosis (CF) is the most common inherited fatal disease in Caucasians and is caused by mutations in the cystic fibrosis transmembrane conductance regulator (CFTR) gene [1]. Despite CF being a multisystemic disease, CF patients mainly die from their respiratory manifestations and complications, characterized by chronic airway infections and nonresolving inflammation. Peculiar and probably unique among human disease conditions is the early and persistent interaction between airway epithelial cells (impaired mucociliary clearance), recruited innate immune cells (mainly neutrophils) and microbial components (mainly bacteria and fungi) within the CF airway compartment. This intimate host-microbe relationship is: (1) mutual and highly complex in its nature, since it evolves/intensifies over time, (2) coregulatory (immune cells kill microbes and vice versa) and (3) affected by several CF medications (particularly antibiotics, antifungals, steroids and DNase). The era of the microbiome, recently extended to the pulmonary microbiome in CF and other lung diseases [2-4], has added another layer of complexity.

Despite fascinating new omics technologies some simple old questions remain surprisingly poorly answered. (1) Is the innate inflammatory response in the CF airway

\section{KARGER}

E-Mail karger@karger.com

www.karger.com/jin protective or harmful? (2) Which innate immune cells that accumulate in CF lungs are protective and which ones cause more harm than protection by releasing proteases and oxidants? (3) Which receptors or downstream pathways could be harnessed to therapeutically interfere with innate immunity in CF lung disease?

In an attempt to address these questions, we have composed a review series on innate immunity in CF lung disease, comprising dedicated reviews from 3 key international opinion leader groups in the field. First, Ralhan et al. [5] provide a comprehensive overview covering and discussing several key players in the innate immune response in the context of the CF lung, i.e. airway epithelial cells, CF characteristic pathogens (focus: bacteria and fungi) and microbial pattern recognition receptors (e.g. Toll-like receptors) as well as a summary of the major innate immune cells that migrate into the inflamed CF microenvironment. Second, Vencken and Greene [6] focus on 2 distinct key players regulating host-pathogen interactions in infective CF lung disease, i.e. Toll-like receptors and microRNAs. Both systems fine-tune and orchestrate the outcome of pathogen sensing and its consequences for mounting immune responses, particularly at the airway epithelial level. Third, Bruscia and Bonfield [7]

Prof. Dr. Dominik Hartl

Children's Hospital and Interdisciplinary Center for Infectious Diseases University of Tübingen DE-72076 Tübingen (Germany)

E-Mail dominik.hartl@med.uni-tuebingen.de 
dig deeper into the complex topic of macrophage plasticity (M1 vs. M2 and beyond) and functionality in CF lung disease, a promising though controversial field of research.

The areas that are not covered by our review series, but are of interest for the CF community and discussed in previous publications are: (1) novel anti-inflammatory therapeutic approaches in CF lung disease, such as roscovitine $[8,9]$, antiproteases [10] and others [11], (2) the quantitatively dominant, though functionally controversial role of neutrophils in CF airways, including disturbed apoptosis, neutrophil extracellular trap (NET) formation and other deviations/alterations [12-17], (3) impairments of the chemokine system in CF $[12,18,19]$ and (4) the microbiome $[3,20,21]$.
Summarizing the studies in the field of innate immunity in CF lung disease reveals the emergence of new players, i.e. microRNAs, novel pathogen-sensing pathways, specialized immune cell subsets, e.g. innate lymphoid cells and myeloid-derived suppressor cells, and the microbiome. All of these, in combination, add several layers of complexity to the puzzle of innate immunity and inflammation in CF lung disease. Comparative studies using in vitro and in vivo (focus: mouse, ferret and pig) approaches as well as biomarker readouts from clinical trials will help to consolidate our mechanistic understanding of the networks in innate immunity, with the final aim to assess their diagnostic and therapeutic applicability in CF lung disease.

\section{References}

1 Mall MA, Hartl D: CFTR: cystic fibrosis and beyond. Eur Respir J 2014;44:1042-1054.

-2 Dickson RP, Huffnagle GB: The lung microbiome: new principles for respiratory bacteriology in health and disease. PLoS Pathog 2015;11:e1004923.

-3 Surette MG: The cystic fibrosis lung microbiome. Ann Am Thorac Soc 2014;11(suppl 1):S61-S65.

4 Dickson RP, Martinez FJ, Huffnagle GB: The role of the microbiome in exacerbations of chronic lung diseases. Lancet 2014;384:691702.

5 Ralhan A, Laval J, Lelis F, Ballbach M, Grund C, Hector A, Hartl D: Current concepts and controversies in innate immunity of cystic fibrosis lung disease. J Innate Immun 2016;8: 531-540.

6 Vencken SF, Greene CM: Toll-like receptors in cystic fibrosis: impact of dysfunctional microRNA on innate immune responses in the cystic fibrosis lung. J Innate Immun 2016;8: 541-549.

7 Bruscia EM, Bonfield TL: Cystic fibrosis lung immunity: the role of the macrophage. J Innate Immun 2016;8:550-563.

8 Witko-Sarsat V: From starfish oocytes to inflammation: the unforeseeable destiny of roscovitine in cystic fibrosis. J Innate Immun 2016;8:327-329.
-9 Meijer L, Nelson DJ, Riazanski V, Gabdoulkhakova AG, Hery-Arnaud G, Le Berre R, Loaec N, Oumata N, Galons H, Nowak E, Gueganton L, Dorothee G, Prochazkova M, Hall B, Kulkarni AB, Gray RD, Rossi AG, Witko-Sarsat V, Norez C, Becq F, Ravel D, Mottier D, Rault G: Modulating innate and adaptive immunity by (R)-roscovitine: potential therapeutic opportunity in cystic fibrosis. J Innate Immun 2016;8:330-349.

10 Griese M, Kappler M, Gaggar A, Hartl D: Inhibition of airway proteases in cystic fibrosis lung disease. Eur Respir J 2008;32:783-795.

11 Cantin AM, Hartl D, Konstan MW, Chmiel JF: Inflammation in cystic fibrosis lung disease: pathogenesis and therapy. J Cyst Fibros 2015;14:419-430.

12 Hartl D, Gaggar A, Bruscia E, Hector A, Mar$\cos$ V, Jung A, Greene C, McElvaney G, Mall $M$, Doring G: Innate immunity in cystic fibrosis lung disease. J Cyst Fibros 2012;11:363382.

13 Tirouvanziam R: Neutrophilic inflammation as a major determinant in the progression of cystic fibrosis. Drug News Perspect 2006;19: 609-614.

14 Dwyer M, Shan Q, D’Ortona S, Maurer R, Mitchell R, Olesen H, Thiel S, Huebner J, Gadjeva M: Cystic fibrosis sputum DNA has NETosis characteristics and neutrophil extracellular trap release is regulated by macrophage migration-inhibitory factor. J Innate Immun 2014;6:765-779.
15 Moriceau S, Lenoir G, Witko-Sarsat V: In cystic fibrosis homozygotes and heterozygotes, neutrophil apoptosis is delayed and modulated by diamide or roscovitine: evidence for an innate neutrophil disturbance. J Innate Immun 2010;2:260-266.

16 Witko-Sarsat V: Neutrophils in the innate immunity conundrum of cystic fibrosis: a CFTRrelated matter? J Innate Immun 2013;5:195196.

17 Zhou Y, Song K, Painter RG, Aiken M, Reiser J, Stanton BA, Nauseef WM, Wang G: Cystic fibrosis transmembrane conductance regulator recruitment to phagosomes in neutrophils. J Innate Immun 2013;5:219-230.

18 Hartl D: Immunological mechanisms behind the cystic fibrosis-ABPA link. Med Mycol 2009;47:S183-S191.

19 Jovic S, Shikhagaie M, Morgelin M, Kjellstrom S, Erjefalt J, Olin AI, Frick IM, Egesten A: Expression of MIG/CXCL9 in cystic fibrosis and modulation of its activities by elastase of Pseudomonas aeruginosa. J Innate Immun 2014;6:846-859.

20 Lynch SV, Bruce KD: The cystic fibrosis airway microbiome. Cold Spring Harb Perspect Med 2013;3:a009738.

21 Zemanick ET, Sagel SD, Harris JK: The airway microbiome in cystic fibrosis and implications for treatment. Curr Opin Pediatr 2011; 23:319-324. 